\title{
Smart phone - A silent killer to oral health
}

\author{
S. Gopalakrishnan ${ }^{1 *}$, G D Gomathi ${ }^{2}$, G Kanimozhi ${ }^{3}$, Gnanasagar ${ }^{4}$ \\ ${ }^{\mathbf{1}}$ Professor, ${ }^{2}$ Post Graduate, ${ }^{3}$ General Dentist, ${ }^{4}$ Senior Lecturer, Dept. of Periodontics, ${ }^{\mathbf{1}, 2,4}$ Thai Moogambigai Dental College \& Hospital, \\ Chennai, Tamil Nadu, ${ }^{3}$ Private Practitioner, India
}

*Corresponding Author: S. Gopalakrishnan

Email: gopalakrishnan_perio@ymail.com

\begin{abstract}
Smart phones are electronic gadget that is used for many purposes other than communication. Past few years data reveals increased smart phone buyers due to introduction of $4 \mathrm{G}$ network. The e-rays emitted from cell phone usually between $301 \mathrm{MHz}$ and $950 \mathrm{MHz}$ depending upon the type of device, frequency and duration of use. Long duration of mobile use can lead to increase in temperature of the exposed areas and surrounding tissues. Mobile phone radiation increases production of singlet oxygen through NADPH oxidase, leading to oxidative stress that forms a major etiological factor for various diseases. Increased exposure to smart phone radiation could have ill effects on human body. Particularly, oral cavity \& Perioral tissues are frequently exposed to mobile radiation compared to other parts of the body. This review highlights the possible mechanism between effects of cell phone radiations on oral tissues.
\end{abstract}

Keywords: DNA, Surrounding tissues, E-Rays.

\section{Introduction}

In the recent decade, there is drastic increase in smart phone usage due to its multipurpose action. This rapid increase in cell phone usage has raised concerns about potential risks associated with exposure to radiation produced by mobiles. E-Rays emitted from cell phone range between $300 \mathrm{MHz}$ and $300 \mathrm{GHz}$. Even when smart phones are not in use, they emit radiation. Mobile phones irrespective of its position, generates radiation that are harmful to the body. It is assumed that, during longer telephonic conversations; smart phone generates heat that spreads to the surrounding tissues in contact. Head and neck region mainly absorbs the heat generated by the smart phone. Exposure to radiation for more than 2 hours is proven to have deleterious effect. ${ }^{1}$ Standing near cell phone towers or smart phones could have non- thermal effect on tissues. $^{2}$ It is proven that electromagnetic radiation from cell phones causes DNA damage. ${ }^{3}$ Primary phase of research has proven the effect of mobile radiation on different organs and tissues of the body. ${ }^{4}$

The amount of radiation emitted by smart phone is dependent on the frequency \& duration of its use. The rate of absorption of radio-waves by human body is governed by factors like size of the body/head, strength of the signal, and age of the person. ${ }^{5}$ Long term use of smart phone has proven to cause light headedness, hearing impairment, sleeplessness, visual disturbance, cancer, etc. ${ }^{6}$

Kids have higher tissue conductivity to E-Rays compared to adults' brain and absorbs radiation deeper in the brain. Studies showed that absorption of microwave radiation is 10 times higher in children than in adults due to the fact that children skull are smaller and thinner compared to adults. ${ }^{7}$ The reason behind this could be the lesser tissue repair due to ageing. Several data supports this concept. ${ }^{8}$

\section{Biological effects of cell phone radiation}

Radio waves from smart phones induce plasma membrane to form NADH oxidase which in turn produces extracellular superoxide that leads to oxidative stress and subsequent carcinogenesis. ${ }^{9}$

Smart phone users have a greater liability of developing gliomas, neuromas and many other types of carcinomas. Tumors are more likely to appear on the frequently used side of the head. Age is found to be a significant factor in the occurrence of complications from smart phones. ${ }^{10}$

Ill effects of using smart phone includes light headedness, migraine, burning sensation in eye, dizziness, sleep deprivement, loss of mental orientation, hallucination, etc. Few studies have quoted adverse effects of cell phone radiation on behavior, sleep, electroencephalograph and sperm count. However, these symptoms could occur even during stress without getting exposed to cell phone radiation. ${ }^{11}$

In contrast, a study conducted by Gary W. Arendash et al. [2010] revealed that the radio waves from cell phones actually reversed Alzheimer's disease in older mice." Exposing old Alzheimer's mice to radio waves from cell phones erased brain deposits of beta-amyloid, thereby preventing the protein's build-up in Alzheimer's mice. ${ }^{12}$

\section{Effects of radiation on mitochondrial DNA}

Human mitochondrial DNA contains 16659 base pairs, codes for 13 proteins including rRNA, tRNA that are necessary for maintaining structural integrity of mitochondria. ${ }^{13}$ Mutations in mtDNA affect ATP synthesis that is associated with neuron degeneration, premature aging, and several other diseases. Long term exposure also induced the production of $8-\mathrm{OHdG}$ in mtDNA compared with that produced in nucDNA. This induction could be correlated with the expression level of DNA polymerase $\gamma$ (POLG), which was essential for the replication of mtDNA. ${ }^{14}$

\section{Radiation effect on oxidative stress}

Loss of one-electron in the outermost shell results in reduction of oxygen, such as singlet oxygen, superoxides, 
peroxides, hydroxyl radical and hypochlorous acid form the reactive oxygen species (ROS). ROS causes oxidative damage of DNA, proteins, lipids and small intracellular molecules, which are associated with contributing factors for alteration in gene expression, intracellular calcium release, cell growth, proliferation, differentiation and apoptosis. RF waves effect on glutamate toxicity results in neurodegenerative diseases including stroke, epilepsy, etc. ${ }^{15}$

Due to the electrical activity of the brain, the nervous system may be the main target for the study of RF radiation effects on biological substrates. The effects on nervous systems includes SH-SY5Y neuroblastoma and SN56 cholinergic cell lines and cortical neurons. ${ }^{16}$

Oxidative stress is occurs as a result of disequilibrium between ROS and antioxidants. ${ }^{17}$ Animal models showed that oxidative stress caused by radio waves can be controlled by increased levels of antioxidants like melatonin, phenyl ester, vitamin $\mathrm{C}$ and $\mathrm{E}$, etc. ${ }^{18}$

\section{Effects of cell phone radiation on oral tissues}

Patient with any metallic appliances or amalgam restorations be more cautious with the usage of cell phone as there could be leaching of metallic ions or mercury that is harmful to the individual. Cell phone radiation causes abnormalities in the cells of oral mucosa.

\section{Effects on salivary gland}

Biochemical study of saliva sample after using mobile phone for 15-30 min showed a significant increase in the superoxide dismutase enzyme in the initial phase followed by a drop. ${ }^{19}$ Cell phone increases the temperature of the surrounding tissues and cause facial nerve dysfunction. The salivary flow rate is altered with increased cytokine expression profile in heavy cell phone users. Cell phones do not cause tumour of the salivary gland directly, but few studies had found adverse effects on orofacial structures. ${ }^{20}$ A significant enlargement in the parotid gland volume was also noted on the frequently exposed side. ${ }^{21}$

\section{Effects on tooth}

No direct adverse effect was noted on the teeth of the affected side. This was confirmed with the study done by Dasdag et al. [2014] who exposed $900 \mathrm{MHz}$ mobile radiation on the enamel of rat teeth and found no alteration in the enamel micro hardness. ${ }^{22}$

\section{Effects on periodontium}

Periodontium is a complex supporting system of the tooth. The periodontal framework undergoes a lot of microbial insult from the dental plaque that leads to inflammation. During inflammation, there is increased oxidative stress which leads to increased tissue damage. Few studies have proven that long term exposure to cell phone radiation causes oxidative stress, which is one of the aggravating factors for periodontitis. Increased radiation could have an impact on periodontal tissues. This was proven by Syed Sirajuddin et $\mathrm{al}^{23}$ who studied the histological effects of ERays on the gingiva of rabbit. There was abundance of inflammatory cells [PMN's]. Exposure to radiations for two hour/day for a period of 10 months produced gingival bleeding in rat model. ${ }^{24}$

\section{Effect on restorations}

Mortazavi SM et al. ${ }^{25}$ found significant release of mercury from dental amalgam restorations due to radio waves emitted from mobile phones. The effects of radio waves on other restorations are yet to be proven.

\section{Discussion}

Mobile radiation causes both thermal and non-thermal changes in human cells. Radiation from smart phone ranges between 0.2 and $1.5 \mathrm{~W} / \mathrm{kg}$. Maximum dose of $2 \mathrm{~W} / \mathrm{kg}$ radiations is the limit to human head. When radiation exceeds the limit, it results in various injurious effects. The International Commission on Non Ionizing Radiation Protection has standardized the frequencies at $300 \mathrm{GHz}$ as limit. ${ }^{26}$

More than 750 million people around the globe use smart phones. The signal frequency differs in every country. Cell phone radiation could be related to periodontitis by increased ROS production. Though mobile radiation alone cannot solely produce periodontitis, it can worsen the periodontal disease. Further probing is required to know the effect of cell phone emitted radiations on periodontal tissues.

\section{Conclusion}

There is no clear literature to prove the direct effect of mobile radiation on periodontal tissues till date. But electromagnetic radiation from smart phones has shown to cause oxidative stress by production of ROS. Oxidative stress is one of the reasons for the cause of periodontitis. Detailed researches on cell phone radiation are required to prove their effects on oral tissues. In general, we know that major purpose of cell phone is for communication. Use of hands-free mode and headphones could reduce the high temperature produced by mobile phone on the surrounding tissues. The lesser use of mobile phone can diminish the noxious effects of mobile radiations.

\section{Source of funding}

None.

\section{Conflict of interest}

None.

\section{References}

1. Conclusions on mobile phones and radio frequency fields. European Commission Scientific Committee on Emerging and Newly Identified Health Risks (SCENIHR). [Last retrieved on 2015 Feb 06].

2. Behari J. Biological responses of mobile phone frequency exposure. Indian J Exp Biol 2010;48(10):959-81.

3. Khurana VG, Teo C, Kundi M, Hardell L, Carlberg M. Cell phones and brain tumors: a review including the longterm epidemiologic data. Surg Neurol 2009;72(3):205-14. doi:10.1016/j.surneu.2009.01.019 
4. Koca O, Gökçe AM, Öztürk MI, Ercan F, Yurdakul N, Karaman MI. Effects of intensive cell phone (Philips Genic 900) use on the rat kidney tissue. Urol J 2013;10:886-91.

5. D'Andrea JA, Emmerson RY, Bailey CM, Olsen RG, Gandhi OP. Microwave radiation absorption in the rat: Frequencydependent SAR distribution in body and tail.

Bioelectromagnetics.1985;6:199-206.

6. JM Kundi The controversy about a possible relationship between cell phone use and cancer. Environ Health Persp 2008; 117: 316-324.

7. Gandhi OP, Lazzi G, Furse CM. Electromagnetic absorption in the human head and neck for mobile telephones at 835 and 1900 MHz? IEEE Trans Microw Theory Tech1996;44:188497.

8. Howlader N, Noone AM, Krapcho M, Miller D, Bishop K, Altekruse SF, et al. (eds). SEER Cancer Statistic Review 19752012, National Cancer Institute. Bethesda, MD. Retrieved January 11, 2016.

9. Friedman J, Kraus S, Hauptman Y, Schiff Y, Seger R: Mechanism of short-term ERK activation by electromagnetic fields at mobile phone frequencies. Biochem $J$ 2007;405(3):559-68. 10.1042/BJ20061653.

10. Hardell L, Carlberg M, Söderqvist F, Mild KH, Morgan LL. Long-term use of cellular phones and brain tumours: Increased risk associated with use for $>$ or $=10$ years. Occup Environ Med 2007;64(9):626-32.

11. Conclusions on mobile phones and radio frequency fields. European Commission Scientific Committee on Emerging and Newly Identified Health Risks (SCENIHR). [Last retrieved on 2015 Feb 06].

12. Gary W. Arendash, Juan Sanchez-Ramos, Takashi Mori, Malgorzata Mamcarz, Xiaoyang Lin, Melissa Runfeldt, et al. Electromagnetic Field Treatment Protects Against and Reverses Cognitive Impairment in Alzheimer's Disease Mice. $J$ Alzheimer's Dis 2010;19:1.

13. Harman D. The biologic clock: the mitochondria? J Am Geriatr Soc 1972;20:145-7.

14. Ueta E, Sasabe E, Yang Z. Enhancement of apoptotic damage of squamous cell carcinoma cells by inhibition of the mitochondrial DNA repairing system. Cancer $S c i$ 2008;99:2230-7.

15. Pan JS, Hong MZ, Ren JL. Reactive oxygen species: a double edged sword in oncogenesis. World J Gastroenterol 2009; 15: 1702-1707.

16. Stagg RB, Thomas WJ, Jones RA. DNA synthesis and cell proliferation in $\mathrm{C} 6$ glioma and primary glial cells exposed to 836.55 MHz modulated radiofrequency field.

Bioelectromagnetics 1997;18:230-6.
17. Del Vecchio G, Giuliani A, Fernandez M. Effect of radiofrequency electromagnetic field exposure on in vitro models of neurodegenerative disease. Bioelectromagnetics 2009;30:564-72.

18. Ozguner F, Bardak Y, Comlekci S. Protective effects of melatonin and caffeic acid phenethyl ester against retinal oxidative stress in long-term use of mobile phone: a comparative study. Mol Cell Biochem 2006;282(1-2):83-8. 10.1007/s11010-006-1267-0.

19. Abu Khadra KM, Khalil AM, Abu Samak M, Aljaberi A. Evaluation of selected biochemical parameters in the saliva of young males using mobile phones. Electromagn Biol Med 2014.

20. Sunil Kumar Mishra, Ramesh Chowdhary, Shail Kumari, Srinivasa B Rao. Effect of Cell Phone Radiations on Orofacial Structures: A Systematic Review. J Clin Diagn Res 2017;11(5):ZE01-ZE05.

21. Bhargava S, Motwani MB, Patni VM. Effect of handheld mobile phone use on parotid gland salivary flow rate and volume. Oral Surg Oral Med Oral Pathol Oral Radiol 2012;114(2):200-6.

22. Dasdag S, Yavuz I, Bakkal M, Kargul B. Effect of long term $900 \mathrm{mhz}$ radiofrequency radiation on enamel microhardness of rat's teeth. Oral Health Dent Manag 2014;13(3):749-52.

23. Syed Sirajuddin, Krishna Kripal, Kavita Chandrasekaran, $\mathrm{P}$ Anuroopa. Effects of Electromagnetic Radiations from Mobile Phone on Gingiva in the Era of $4 \mathrm{~g}$ Lte-An In Vivo Study in Rabbits. Dent 2018;8:10

24. Kaya FA, Dasdag S, Kaya CA, Akdag MZ, Yavuz I, Kilinc N, et al. Effects of radiofrequency radiation by $900 \mathrm{MHz}$ mobile phone on periodontal tissues and teeth in rats. J Anim Vet Adv 2008;7:1644-50.

25. Mortazavi SM, Daiee E, Yazdi A, Khiabani K, Kavousi A, Vazirinejad R, et al. Mercury release from dental amalgam restoration after magnetic resonance imaging and following mobile phone use. Pak J Biol Sci 2008;11(8):1142-46.

26. Litvak E, Foster KR, Repacholi MH. Health and safety implications of exposure to electromagnetic fields in the frequency range $300 \mathrm{~Hz}$ to $10 \mathrm{MHz}$. Bioelectromagnetics. 2002;23:68-82.

How to cite this article: Gopalakrishnan S, Gomathi $\mathrm{G}$ D, Kanimozhi G, Gnanasagar. Smart phone - A silent killer to oral health. Int $J$ Periodontol Implantol 2019;4(3):73-5. 